\title{
A study on farmer's perception on ill effects of agro chemicals in north eastern part of Karnataka
}

\section{K. K. Shashidhara}

Department of Agricultural Extension Education, College of Agriculture, Bheemarayangudi, University of Agriculture Sciences, Raichur, (Karnataka), INDIA

E- Mail: agrishashi@gmail.com

Received: August 21, 2016; Revised received: May 5, 2017; Accepted: October 5, 2017

Abstract: The present study was conducted in Yadgir district of Karnataka to know about the perception of farmers on the ill effects of agro chemicals. One hundred and twenty farmers were interviewed personally with the help of pre-structured schedule. The results revealed that a large number of respondents had perceived delay in ripening $(70.83 \%)$, less resistance to diseases $(76.66 \%)$, through emission of toxic gases $(80.83 \%)$ and changes in soil organic matter decomposition (80.00\%). Cent per cent respondents expressed resistance developed to pesticides by helicoverpa, spodoptera and parthenium and beneficial organisms like earth worms and predators were affected. Killing of natural enemies by pesticides affect Trichograma $(80.00 \%)$ and lady bird beetle $(75.00 \%)$, while handling agro chemicals cent per cent perceived it is going poison human body. The correlation indicates attitude towards chemical fertilizers, extension participation and mass media had shown positive highly significant at $1 \%$ level. Regarding factors influencing on agro chemicals land holding and education observe 50.63 per cent of variation. On the other hand farmers were suggested to make the availability of pest resistance variety by majority $(83.33 \%)$ of the respondents.

Keywords: Agro chemicals, Environmental pollution, Health problems, III effects, Pesticides

\section{INTRODUCTION}

Agriculture and the environment have always been closely inter-linked. We depend upon the environment, on the resources of land, water, sunlight and biological organisms for agricultural production. The environment provides opportunities for agriculture, but it is hampered by several activities. The environment of the world is slowly degrading due to industrial and agricultural emissions and the people are very anxious about the degradation or pollution as this may cause serious damage to lives on the earth (Brodt et al., 2011). Today, it is an established fact that agriculture sector beside industry is another major polluter of environment on a local, regional and global basis (Muhammad and Ruslan, 2012).

About 70 percent of pesticides is being used in developing countries and remaining 30 per cent in developing countries. More than 1000 agro chemicals are being manufactured and used for agriculture as well as public health purposes. About 90 per cent of this quantity is comprised of insecticides and herbicides with about equal share each. Fungicides represent about 10 percent of the total. Use of pesticides in India is increasing at the rate of two to five per cent per annum and is about three per cent of total pesticides used in the world. About 90,000 metric tons of technical grade pesticides are currently produced and more than 67 per cent is used in agriculture sector alone (Nigam and Murthy, 2000).

Indiscriminate use of high dosage fertilizers has caused several problems on the farm as well as outside farm. Plants become more susceptible to pests and diseases and their control could be effectively done by using high potency poisonous chemicals. As a result, their residue on plants and in the soil had lead to health hazards (Malathi and Bangarusamy, 2001). Similarly, excess nitrogen as nitrate and phosphate leached through the soil and entered natural sources of drinking water also responsible for health hazards. The chemical detrimental effects of fertilizers on plants are reduction in germination, retardation in seedling growth, scorching and increased susceptibility to diseases (Asha et al., 2001). Methemoglobinemia (blue baby disease) in infants, cancer and respiratory illness in human beings, eutrophication and plant toxicity due to excessive availability of inorganic and organic nitrogen in surface water and soil (Addiscot, 1996).

In order to mitigate these health hazards and bring out natural balance and protection of ecosystems, the organic movement has started in several parts of the world, in which no chemical fertilizer and plant protection chemical is used in the cultivation of field crops, vegetables and fruits. The investigation of farmer's perception regarding pesticides impact on sustainable environment is an active area of research in crop sci- 
ence, agricultural extension and environmental studies. Already, more than a few studies have been conducted regarding farmers' perception, but they focused on climate change, untreated wastewater irrigation, or soil degradation etc. The present study is an attempt to investigate the farmer's perceptions towards ill effects of agro chemicals, their relationship with socioeconomic factors and suggestive measures to minimize the ill effects of agro chemicals as perceived by farmers.

\section{MATERIALS AND METHODS}

Descriptive survey design for data collection was adopted in the present study. The study was conducted in Yadgir district of Karnataka in India. The main crops grown in the district were paddy, cotton chili, cabbage, carrot, tomato and cucumber (Anonymous, 2015). Because of favourable climatic conduction prevailing in the study, majority of crops were affected by pests and diseases. In order to mitigate these pest and diseases, the farmers were heavily relying on agrochemicals. Form this district Yaddgir and Shahapur taluks were selected due to maximum area under irrigation and cultivation. Further two villages were selected from each taluk which have maximum area under irrigation and cultivation. From each village, 15 farmers were selected randomly, who were growing mainly cotton, paddy and chili making a total of 120 farmer respondents.

Data were collected using a well structured pre-tested interview schedule and direct observation (Kumar, 2012). The interview schedule had three sections: (i) information on socio-economic profiles (ii) perceptions farmer towards the ill effects of agro chemicals and (iii) Measures to minimize the ill effects of agro chemicals. The socioeconomic characteristics studied were age, education, land holding, annual income, attitude towards chemical fertilizers, extension participation, institutional participation and mass media use (Venkataramaiah, 1990). A teacher made perception test was developed to measure the perception level of farmers about the ill effects caused by indiscriminate use of agro chemicals. Information regarding the different ill-effects of agricultural chemicals like their effect on human health, toxicity to animals, hazardous to environment and non-target organisms, resistance developed by pests, etc., was collected from a good number of relevant literature, books and consulting experts from University of Agricultural Sciences in the concerned departments of like entomology, soil science, agronomy, plant pathology, soil science, environmental science and horticulture. To get the rural people's perception towards the ill effects of agro chemicals, 14 selected indicators on ill effects of indiscriminate use of agro chemicals were incorporated in the schedule and their degree of importance were measured by yes or no responses by the respondents. The observed data were analyzed on MS Excel and Statisti- cal Package for Social Sciences (SPSS) software with the level of significance set at $p<0.05$. The statistical tools viz., frequency (f), percentage (\%), average (x), standard deviation coefficient of correlation and simple regression were applied for analysis of the data as per Snedecor and Cochran (1967).

\section{RESULTS AND DISCUSSION}

The results on the ill effects of agro chemicals as perceived by the farmers were presented in the Table 1 . Regarding excuses use of nitrogenous fertilizers and its ill effects, 16.66 per cent of the farmers perceived that it increased the level of nitrates in soil, delays ripening of grains $(70.13 \%)$ and thirty per cent of the farmers perceived it leads to lodging of crops. Further, twothird of the respondents $(76.66 \%)$ believed it was less resistance to diseases. Excessive quantity of nitrates in drinking water causes Blue-baby syndrome was perceived by only 6.66 percent of the respondents.

Regarding the changes or alter in fundamental soil properties brought about by pesticides, majority $(80.00 \%)$ of the farmers perceived that it affects on the organic matter decomposition and only 6.66 percent perceived it affects on the nitrogen transformation. Whereas 1.66 and 52.50 percent of the farmer respondents perceived the pesticides affects soil process such as phosphorus availability and soil enzyme activity respectively. Cent per cent of the farmer respondents perceived fertilizer and pesticide factories pollute the environment by allowing the factory effluents run into rivers. While 80.83 per cent of respondent's perceived factories polluted the air by the emission of toxic gasses. It has been noted that most the crops requires lower rates of agro chemicals to increase yield and higher rates suppress yield (Glover-Amengor and Tetteh, 2008). The results clearly indicate that the respondent farmers had the effects of the use of pesticides. They were aware of the fact that pesticides cause pollution, can affect soil fertility and impose toxic effects on the soil. Commercial inorganic fertilizer makes soil hard and difficult to cultivate and kill beneficial organisms in the soil (Robert, 2013).

Perception of farmer towards the ill effects of pesticides is indicated that, 16.66 percent of the farmer perceived the ban on organochlorine insecticides such as DDT, BHC and Aldrin persist in soil for a longer period. While 5.00 per cent of the farmers perceived these chemicals were translocated from soil to plants. An equal percent $(6.66 \%)$ farmer respondents perceived that they were detected in all water bodies make unsafe for drinking purpose and residues of these chemicals were detected in human breast milk, blood and adipose tissues increasing the risk of cancer. Whereas 10.00 per cent of the respondents perceived resides detected in almost all food and feed stuff which are reported to be carcinogenic. The resistance developed by pests to the pesticides, majority $(69.16 \%)$ of farmers perceived 
Table 1. Perception of farmer towards the ill effects of agro chemicals $(n=120)$.

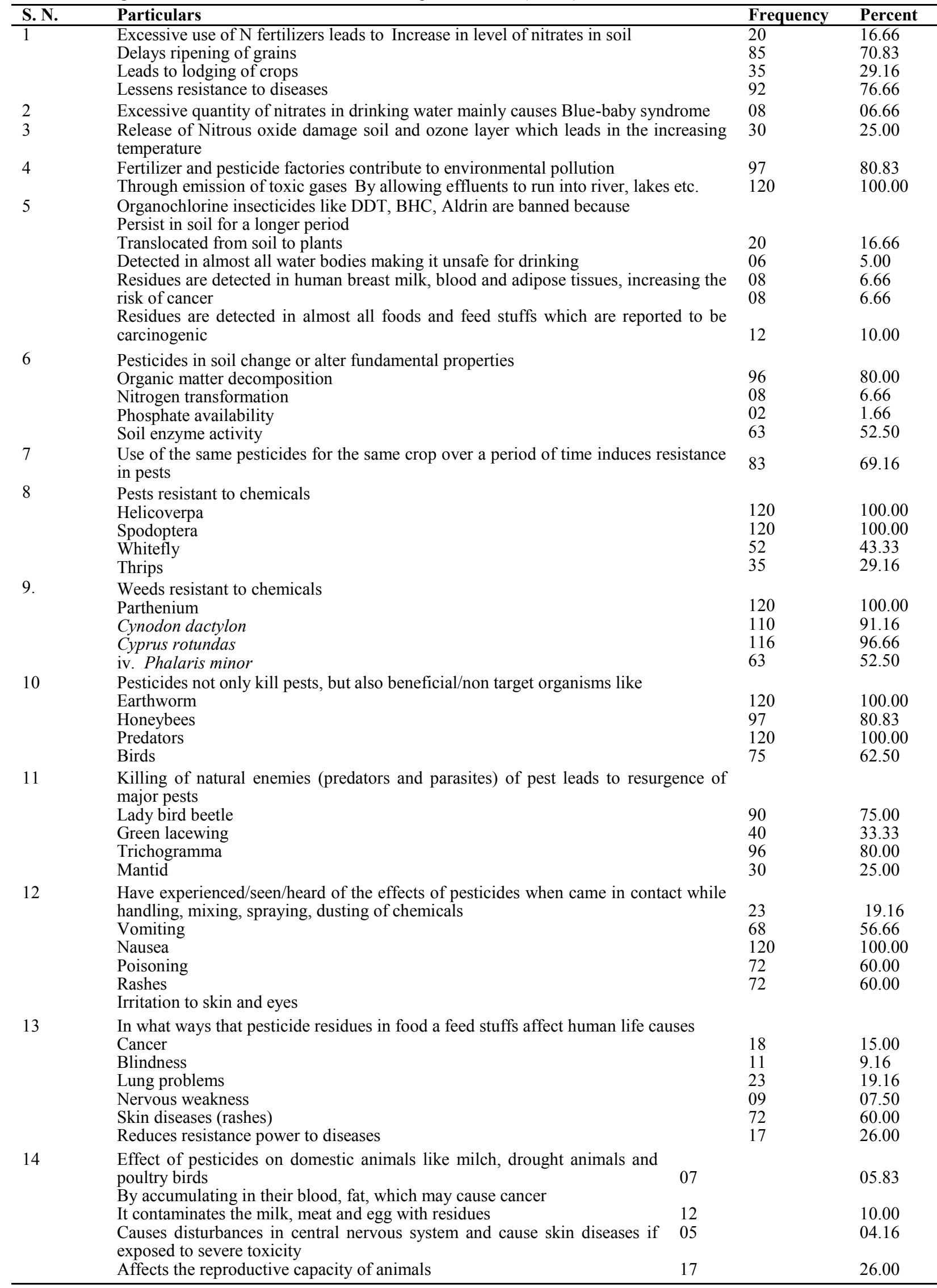


Table 2. Correlation between perception of ill effects of agro chemicals with other research variables $(n=120)$.

\begin{tabular}{llc}
\hline S. N. & Characteristics & $\begin{array}{c}\text { Correlation } \\
\text { coefficient (r) }\end{array}$ \\
\hline X1 & Age & $0.0548 N S$ \\
X2 & Education & $0.1667^{*}$ \\
X3 & Land holding & $0.1351 N S$ \\
X4 & Annual income & $0.1519^{*}$ \\
X5 & Attitude towards chemi- & $0.1759^{* *}$ \\
& cal fertilizers & \\
X6 & Extension participation & $0.2332^{* *}$ \\
X7 & Institutional participation & $0.1691^{*}$ \\
X8 & Mass media use & $0.2022^{* *}$ \\
\hline
\end{tabular}

NS - Non significant, * Significant at 5 per cent level, ** Significant at 1 per cent level

it was due to the frequency of resistant genes present in the population and the rate at which the pest population breeds (Number of generation/year). Many of the chemicals used in pesticides are persistent soil contaminants, whose impact may endure for decades and adversely affect soil conservation. The use of pesticides decreases the general biodiversity in the soil. Not using the chemicals results in higher soil quality (Johnston, 1986). The insecticides DDT, methyl parathion, and especially pentachlorophenol have been shown to interfere with legume-Rhizobium chemical signalling. Reduction of these symbiotic chemical signalling results in reduced nitrogen fixation and thus reduced crop yields (Rocket, 2007). Eutrophication of lake and river water bodies, nitrate pollution of ground water, increased emission of gaseous nitrogen and metal toxicities are the major fertilizer related environmental damages (Katyal, 1979).

Regarding the pests and weeds which have become resistant to the chemicals cent per cent of the farmers perceived Helicoverpa and Spodoptera had become resistance. Whereas, 43.00 and 29.16 percent perceived whitefly and thrips become resistant respectively. With regard to resistance to weeds to herbicides majority of them perceive that Parthenium (100.00\%), Cynodondactylon (91.16\%), Cyprus rotundas (96.66\%) and Phalaris minor (52.50\%) was perceived resistant. Pests may evolve to become resistant to pesticides as a result of continued use of pesticides in a particular environment. Many pests will initially be very susceptible to pesticides, but some with slight variations in their genetic makeup they become resistant and therefore survive to reproduce (James, 2011). Razali (1997) reported that it is becoming difficult to produce on many of the farms without using pesticides. That's why, farmers use different types of pesticides. It is important for all the farmers to have an perception of the appropriate use of various pesticides needed for different crops.

Regarding harmful effect of pesticides to beneficial/ non-target organisms cent per cent of farmer's perceived organisms such as earthworm and predators were affected. While 80.83 and 62.50 percent perceived honey bees and birds are also affected. The effect of chemicals on natural predators 80.00, 75.00, 30.33 and 25.00 per cent of the respondents perceived it affected tricogramma, lady bird beetle, green lacewing and mantids respectively. Some natural pollinators, such as honeybees and butterflies, are very sensitive to pesticides. Pesticides can kill bees and are strongly implicated in pollinator decline, the loss of species that pollinate plants, including through the mechanism of Colony Collapse Disorder (Hackenberg, 2007). Some pertinent examples associated with birds are killed as a result of pesticides includes diazinon and carbofuran which are well documented as causing bird kills in many parts of the world (Kegley, 1999).

Regarding the ill effect of pesticides on human health while handling chemicals 19.16 per cent perceived it induced vomiting at the time of application and nausea was perceived by 56.66 per cent by the farmers. Cent per cent of the farmers perceived chemical induced poisoning. Whereas an equal percent $(60.00 \%)$ of the respondents perceived that it affect rashes and irritation to skin and eyes. Pesticide residues in food stuffs affect human life causes cancer $(15.00 \%)$, blindness $(9.16 \%)$, lung problems (19.16), nervous weakness (7.50), skin diseases or rashes $(60.00 \%)$ and reduces resistance power to diseases $(26.00 \%)$ was perceived by the respondents. Elzimaity (1998) reports that change in one or more of the physical, chemical properties, or all or some of the vital components of the environment would lead to adverse effects to humans, plants and animals. This high level of knowledge about pesticide hazards which the end users of pesticides have is important for the prevention of acute poisoning (Hong, 2007), (Adeola, 2012). Pesticides generally affect people's health, cause skin, eye irritation, stomach irritation, vomiting and dizziness (Robert, 2013). Pesticide residues affect human health. In fact, pesticide application has become a great threat to human health (Buczynska, and Szadkowska-Stanczyk, 2005), (Elfvendahl et al., 2004), Leyket al., 2009), (Sivanesan et al., 2004). Studies have shown that long-term lowdose exposure to pesticides leads to the development of respiratory diseases such as asthma (Hoppin et al., 2002). Such exposure also leads to reduced sperm quality and sperm count, causing sterility (Tuc, 2007) (Govinda, 2014). Exposure to pesticides can range from mild skin irritation to birth defects, tumours, genetic changes, blood and nerve disorders, endocrine disruption, and even coma or death (Miller, 2004). Pesticides can enter the human body through inhalation of aerosols, dust and vapor that contain pesticides, through oral exposure by consuming contaminated food and water; and through dermal exposure by direct contact with pesticides with skin (Sacramento, 2008). Regarding the ill effects of chemicals on domestic animals like milch, draft animals and poultry birds, only a 
Table 3. Factors influencing perception towards ill effects of agro chemicals.

\begin{tabular}{lllll}
\hline S. N. & Characteristics & Regression coefficient & S.E. of Standard error & 't' value \\
\hline X1 & Age & -0.0059 & 0.0093 & -0.6356 \\
X2 & Education & $0.1555^{*}$ & 0.7580 & 2.0512 \\
X3 & Land holding & $0.1632^{*}$ & 0.0541 & 2.6988 \\
X4 & Annual income & 0.0292 & 0.0694 & 0.5943 \\
X5 & Attitude towards chemical fertilizers & 0.0160 & 0.0122 & 1.3176 \\
X6 & Extension participation & 0.1050 & 0.0770 & 1.3637 \\
X7 & Institutional participation & 0.0191 & 0.0844 & 0.2268 \\
X8 & Mass media use & 0.0732 & 0.0495 & 1.4774 \\
\hline
\end{tabular}

$\mathrm{R} 2=0.5063, \mathrm{~F}$ value $=2.6924^{* *}, *$ Significant at 5 per cent level, $* *$ Significant at 1 per cent level

Table 4. Measures to minimize the ill effects of agro chemicals $(n=120)$.

\begin{tabular}{llll}
\hline S. N. & Suggestions made by farmers & Frequency & Per cent \\
\hline 1 & Making available pest resistant varieties & 100 & 83.33 \\
2 & Organizing training on eco-friendly practices & 88 & 73.33 \\
3 & Encouraging farmers to grow organic crops through subsidies, technical guidance etc., & 82 & 68.06 \\
4 & Ensure strict quality control measures for pesticides & 80 & 66.66 \\
5 & Use of bio-pesticides and bio-fertilizers must be increased & 73 & 60.59 \\
6 & Use of bio-control agents in the control of pests must be increased & 69 & 57.27 \\
7 & Give premium price for organically grown crops & 64 & 53.12 \\
8 & Educate public and farmers about the environmental issues & 49 & 40.67 \\
9 & Establishing a network of farmers adopting organic farming & 44 & 36.52 \\
10 & Introducing environmental education at the secondary level & 25 & 20.75 \\
\hline
\end{tabular}

mere percent of farmer respondents perceived it will accumulate in their blood and fat, which causes cancer $(5.83 \%)$, it contaminates the milk, meat \& egg with residues $(10.00 \%)$ and causes disturbances in the central nervous system and causes skin diseases if exposed to severe toxicity $(4.16 \%)$. More than one-fourth of the respondents perceived chemicals affected the reproductive capacity of the animals $(26.00 \%)$. The ill effects of indicated above seem to be complex to understand and remember. Most of them need scientific analysis to identify and determine a cause for the ill effect noticed. It can be said that many of the above mentioned ill effects are beyond the comprehension of farmer's level of understanding. Probably these facts might be the reasons for the less perception by the farmer respondents. Pesticides are sprayed onto food, especially fruits and vegetables, they secrete into soils and groundwater, which can end up in drinking water and pesticide spray can drift and pollute the air. In some areas, pesticides have created the pollution problems and the environmental issues due to their excessive use. Similarly the damage of toxic pesticide contamination, however, farmers had the lowest level of knowledge of the pesticide damage on atmospheric layer/cover and the growing plants (Alteieri, 2000).

Correlation between perceptions on ill effects of agro chemicals with other research variables: The results in the table indicated that there is a direct correlation between the level of education, annual income, institutional participation with 0.05 correlation coefficient and attitude towards chemical fertilizers, extension participation, mass media use (as independent variable) with 0.01 correlation coefficient on perception of ill effects of agro chemicals (as the dependent variable) with potential level of $0.1667,0.1519$,
$0.1691,0.1759,0.2332,0.2022$ respectively. This means that the farmers with higher the higher levels of education will have increased annual income, attitude towards chemical fertilizers, extension participation, institutional participation and mass media use. Increased level of perception on the adverse effects of agrochemicals and the high level of income and education were important factors to have the assessment of mental approach of the farmers and the usefulness of material about the adoption of modern methods and practices. Educated farmers can easily deal with pesticides and are their awareness level on the consequences of using the incorrect pesticides and the negative effects inappropriate use on the environment is certainly higher. As revealed in table there is positive correlation between personal characteristics of respondents and their perception regarding the ill effects of agrochemicals. The level of perception of respondents about the adverse effects of agrochemicals is significantly influenced by the parameters like the level of education, education, annual income, institutional participation, attitude towards chemical fertilizers, extension participation and mass media use (Banjo et. al. 2010 and Al-Zaidi et al., 2011).

Factors influencing on ill effects of agro chemicals: Farmer's show that an overall satisfaction level on perception of the ill effects of agro chemicals. It was observed that eight independent variables included in the study could explain 50.63 percent variation in the perception level of farmers towards ill effects of agro chemicals. Out of eight variables considered, only land holding and education were found to be positively significant in influencing the perception of farmers towards ill effects of agro chemicals with regression co-efficient of 2.0512 and 2.6988 at 0.05 level of sig- 
nificance respectively. Hence, these two variables could be termed as good predictors of the perception of farmers towards ill effects of agro chemicals. Landholding and education were the most significant socioeconomic variables affecting the farmer's perception of the importance of the ill effects of agro chemicals. Those who have larger landholdings perceive the ill effects of agro chemicals. This indicated that the selected variables could explain fifty per cent of the variation in the perception and remaining fifty percent variation could be attributed to some other variables which were not indicated in the study. Even there was a significant change in the perception of farmers towards ill effects of agro chemicals can be brought about by brining positive changes in these two variables. This leads to the conclusion that land holding and education had significantly contributed to increase in perception of farmers towards ill effects of agro chemicals. The factors found to be associated with pesticide poisoning in this study indicate that implementation of specific intervention strategies and education of farmers is needed in order to improve safe handling, use and disposal of pesticides and reduce incidents of acute pesticide poisoning (Ncube et al. (2011).

Measures to minimize the ill effects of agrochemicals: It is found that majority $(83.33 \%)$ of the respondent's suggested making the availability of pest resistant varieties. This could be attributed to the reason that there are only few companies releasing good high yielding resistant varieties and which are costlier to purchase. Nearly three-fourth $(73.33 \%)$ of respondents said organizing training on eco-friendly management practices. This might be due to the rising costs of agro chemicals, which are very high, and resistance in pest is also being observed. $68.06 \%$ of the respondents suggested encouraging farmers to grow organic crops through subsides, technical support, etc. Now a day's organic farming is gaining more importance and they were getting a good return from growing organically grown crops. Ensure quality control measures for pesticides were suggested by respondents.

\section{Conclusion}

The run off agrochemicals and their effluents into river and lakes leads to pollution and also affecting the eco system. The over usage of pesticides leads to resistance in Helicoverpa \& Spodoptera and also kills beneficial organisms and insects. We must use alternative methods in pest control including expanding biological agriculture, natural and natural enemies to combat pests, pest control mechanical activities, chemical pesticides with a lower degree of toxicity and timely use of pesticides in order to effectiveness of pesticides, so it's very important that Integrated Pest Management Centre, State Department of Agriculture, University of Agricultural Science and Environmental Pollution Board should make integrated and concrete efforts to provide the required perception about environmental hazards caused by indiscriminate use of agro chemicals.

\section{REFERENCES}

Addiscot, T.M. (1996). Fertilizers and nitrate leaching. Agricultural chemicals and environment. (Edt). R. E. Hoster and R. M. Harrison. The royal society of Chemistry, Cambridge, pp.1-17

Adeola, R.G. (2012). Environmental Effects of Pesticides Use in Vegetable Production by Farmers in Ogbomoso, Nigeria Global. Journal of Science Frontier Research Agriculture \& Biology, 12 (4): 72-78

Alteieri, M.A. (2000). Modern Agriculture: Ecological impacts and the possibilities for fully sustainable farming. University of California, Berkeley, United States of America

Anonymous (2015). Yadagiri District Statistical Information 2014-15, District Statistical Information Office, Yadagiri, Karnataka

Al-Zaidi, A. A., Elhag, E. A. Al-Otaibi S. H. and Baig, M. B. (2011). Negative effects of pesticides on the environment and the farmers awareness in Saudi Arabia: A case study. The Journal of Animal \& Plant Sciences, 21 (3):605-611

Asha, K.R., Ameena, M. and Geetha Kumari, V.L. (2001). Excessive use of chemical fertilizers harmful. Kisan World, 28(9): 36-37

Banjo, A.D., Aina, S.A. and Rije, O.I., ( 2010). Farmers knowledge and perception towards herbicides and pesticides usage in Fadama Area of Okun-Owa, Ogun State of Nigeria, African Journal of Basic \& Applied Sciences, 2 (5-6): 188-194

Brodt, Six S. J., Feenstra, G., Ingels, C. and Campbell, D. (2011). Sustainable agriculture. Nature Education Knowledge, 3(3): 1

Buczynska, A. and Szadkowska-Stanczyk, I. (2005). Identification of health hazards to rural population living near pesticide dump sites in Poland. International Journal of Occupational Medicine and Environmental Health, 18: 331-339

Elfvendahl, S., Mihale, M., Kishimba, M.A. and ylin, H. (2004). Pesticide pollution remains severe after cleanup of a stockpile of obsolete pesticides at Vikuge, Tanzania. Ambio, 33: 503-508

Elzimaity, M.S. (1998). Applications of integrated pest management in agriculture. Dawn Publications and Distribution, Riyadh, Kingdom of Saudi Arabia

Govinda Bhandari (2014). An Overview of Agrochemicals and Their Effects on Environment in Nepal, Applied Ecology and Environmental Sciences, 2(2): 66-73

Glover-Amengor, M. and Tetteh, F.M. (2008). Effect of Pesticide Application Rate on Yield of Vegetables and Soil Microbial Communities. West African Journal of Applied Ecology, 12(1)

Hackenberg, D. (2007). Letter from David Hackenberg to American growers. PlattformImkerinnen Austria.

Hong Zhang and Yonglong, Lu. (2007). End-users' knowledge, attitude, and behaviour towards safe use of pesticides: a case study in the Guanting Reservoir area. China. Environmental Geochemistry and Health, 29 (6): 513-520

Hoppin, J.A., Umbach, D.M, London, S.J., Alavanja, M.C.R. 
and Sandler, D.P. (2002). Chemical predictors of wheeze among farmer pesticide applicators in the agricultural health study. American Journal of Respiratory and Critical Care Medicine, 5: 683-689

James Tano Zacharia (2011). Ecological Effects of Pesticides, Pesticides in the Modern World - Risks and Benefits, Dr. Margarita Stoytcheva (Ed.), ISBN: 978-953307-458-0, In Tech, Available from: http:// www.intechopen.com/ books/pesticides-in-the-modernworld-risks-and-benefits/ecological-effects-of pesticides.

Johnston, A.E. (1986). Soil organic-matter, effects on soils and crops. Soil Use Management, 2: 97-105

Katyal, J. C. (1979). Fertilizer use and impact on environment, FAI seminar on fertilizer, Agriculture and national economy. The fertilizer association of India, New Delhi, December 4-6: 1-8

Kegley, S. (1999). Disrupting the Balance, Ecological Impacts of Pesticides in California, California, USA.

Kumar, R. (2012). Research Methodology - A step by step guide for beginners. Dorling Kindersley (India) Pvt. Ltd., New Delhi, India.

Leyk, S., Binder, C.R. and Nuckols, J.R. (2009). Spatial modelling of personalized exposure dynamics: The case of pesticide use in small-scale agricultural production landscapes of the developing world. International Journal of Health Geographics, 8(17): 1-16

Malathi, D. and Bangarusamy, U. (2001). Harmful effects of agricultural chemicals. Agro-India Handbook on Food processing. R. K. Business International, Bangalore, 232-235

Miller, G.T. (2004). Sustaining the Earth, 6th edition. Thompson Learning, Inc. Pacific Grove, California, USA.

Muhammad Humayun Kabir and Ruslan Rainis (2012). Farmers Perception on the Adverse Effects of Pesticides on Environment: The Case of Bangladesh, International Journal of Sustainable Agriculture, 4 (2): 25-32
Ncube, N., Fogo, C., Bessler. P., Jolly. C.M. and Jolly, D.E. (2011). Factors associated with self respected symptoms of acute pesticide poising among farmers in North Western Jamaica. Archives of Environmental and occupational Health, 66: 65-74

Nigam, G.L. and Murthy, K.S. (2000). An optimum use of pesticides in Integrated Pest Management Technology. Pesticides Information, 25(4): 6-9

Razali and Kamal (1997). For a better environment. Foundation University Students. King Saud University; Riyadh, Kingdom of Saudi Arabia

Robert, T. and Ngidlo, (2013). Impacts of pesticides and fertilizers on soil, tail water and groundwater in three vegetable producing areas in the Cordillera region, Northern Philippines, American Journal of Experimental Agriculture, 3(4): 780-793

Rocket, R. (2007). Down on The Farm? Yields, Nutrients and Soil Quality. Scienceagogo.com. Retrieved on September 15, 2007. http://www.scienceagogo.com/news/ farming.shtml

Sacramento, C.A. (2008). Department of Pesticide Regulation "What are the Potential Health Effects of Pesticides?" Community Guide to Recognizing and Reporting Pesticide Problems: 27-29

Sivanesan, S.D., Krishnamurthi, K., Wachasunder, S.D. and Chakrabarti, T. (2004). Genotoxicity of pesticide waste contaminated soil and its leachate. Biomedical and Environmental Sciences, 17: 257-265

Snedecor, G.W. and Cochran, W.G. (1967). Statistical Methods. Iowa State University Press, Ames, Iowa-50010

Tuc V.P, Wangsuphachart V, Tasanapradit P, Fungladda W, Van Trong P, \&Nhung N.T. (2007). Impacts of pesticide use on semen characteristics among rice farmers in Kienxuong District, Thaibinh Province, Vietnam. Southeast Asian Journal of Tropical Medicine and Public Health, 3: 569-575

Venkataramaiah, P. (1990). Development of socio-economic status scale, Ph.D. Thesis, Department of Agricultural Extension, UAS, Bangalore 